\title{
Performance Characteristic of Cold Recycled Mixture with Asphalt Emulsion and Chemical Additives
}

\author{
Shaowen Du \\ Department of Road Engineering, Chang'an University, Mail Box No. 329, Middle Section of Nan Er Huan Road, Xian, \\ Shaanxi 710064, China \\ Correspondence should be addressed to Shaowen Du; dushaow@gmail.com
}

Received 21 August 2015; Revised 30 October 2015; Accepted 1 November 2015

Academic Editor: Anna Richelli

Copyright (C) 2015 Shaowen Du. This is an open access article distributed under the Creative Commons Attribution License, which permits unrestricted use, distribution, and reproduction in any medium, provided the original work is properly cited.

\begin{abstract}
Three types of chemical additives were used to modify asphalt emulsion recycled mixture. These chemical additives include composite Portland cement (CPC), hydrated lime (HL), and a combination of hydrated lime and ground-granulated blast-furnace slag (GGBF). The influence of different additives on the recycled mixture performance was investigated by volumetric and strength tests, moisture susceptibility test, rutting resistance test, and low temperature bending test. To better understand its performance characteristic, the microstructure images of the recycled mixture were observed by environmental scanning electron microscope (ESEM). Test results demonstrate that the performance improvement of the emulsion recycled mixture depends on the types and content of chemical additives. Several recommendations are presented for the selection of chemical materials. Based on ESEM image analysis, the interface bonding mechanism is proposed to explain the performance characteristic of the recycled mixture with asphalt emulsion and cementitious materials.
\end{abstract}

\section{Introduction}

The performance of asphalt pavement in service is gradually deteriorated due to vehicle load repetition and environmental factors. When pavement condition reaches a certain unacceptable level, it has to utilize reasonable rehabilitation methods to restore its performance. In addition to its environmental benefits, pavement recycling technologies provide cheaper, faster, and less traffic disruptions alternative to conventional reconstruction strategies $[1,2]$. Cold recycling is one of the most popular pavement recycling methods. During cold recycling, existing asphalt pavement is pulverized by cold milling machine. It is suggested to use $100 \%$ reclaimed asphalt pavement (RAP) to design cold recycled mixture. In some cases, new aggregates are also used to adjust the RAP gradation. These loose aggregates are stabilized by bonding materials and recompacted into a base course of new pavement structure without the application of heat [3]. Normally, RAP is treated as "black stone" and stabilized by bonding materials to design cold recycled mixture. The most common stabilizing materials for cold recycling mixtures are mixing grade asphalt emulsions because they are liquid at ambient temperatures and can be easily dispersed throughout the mix $[3,4]$.

Asphalt emulsion has been used to stabilize RAP with a long history. However, there are still some problems on the performance properties of the emulsion recycled mixture, for example, low early-stage strength, inadequate resistance to moisture damage, and permanent deformation [3, 4]. These shortcomings are derived from the breaking and curing characteristic of asphalt emulsion. It has been demonstrated that asphalt emulsion needs extended curing time to restore the rheological properties of asphalt binder before being emulsified $[5,6]$. Since the early 1970 s, many studies have shown that cement can improve the early mechanical strength and performance properties of asphalt emulsion mixture [7-10]. With the development of cold recycling technology, some researches also recommended using cement to modify the cold recycled mixture with asphalt emulsion. The improvement of cement on the performance properties of asphalt emulsion recycled mixture is also verified by some studies [11-13]. Moreover, some researchers suggest using hydrated lime, fly ash, or other chemical materials to enhance the performance properties of the emulsion recycled mixture 
TABLE 1: Test results of extracted asphalt binder.

\begin{tabular}{lc}
\hline Properties & Value \\
\hline Penetration $\left(25^{\circ} \mathrm{C}, 100 \mathrm{~g}, 5 \mathrm{~s}\right) / 0.1 \mathrm{~mm}$ & 27 \\
$15^{\circ} \mathrm{C}$ ductility $/ \mathrm{cm}$ & 3.8 \\
$5^{\circ} \mathrm{C}$ ductility $/ \mathrm{cm}$ & 0 \\
Soft pointing $(\mathrm{R} \& \mathrm{~B}) /{ }^{\circ} \mathrm{C}$ & 64.6 \\
\hline
\end{tabular}

TABLE 2: Test results of cationic asphalt emulsion.

\begin{tabular}{lcc}
\hline Properties & Specification & Value \\
\hline Residue by distillation/\% & 55 & 58 \\
1.18 sieve test $\%$ & $\leq 0.1$ & 0.06 \\
$5 \mathrm{~d}$ storage stability/\% & $\leq 5$ & 0.1 \\
$\mathrm{pH}$ & - & 5.11 \\
Residue test & & \\
Penetration $\left(25^{\circ} \mathrm{C}, 100 \mathrm{~g}, 5 \mathrm{~s}\right) / 0.1 \mathrm{~mm}$ & $45-150$ & 59 \\
$15^{\circ} \mathrm{C}$ ductility $/ \mathrm{cm}$ & $\geq 40$ & 72 \\
Soft pointing $(\mathrm{R} \& \mathrm{~B}) /{ }^{\circ} \mathrm{C}$ & - & 48 \\
\hline
\end{tabular}

[14-16]. However, there is still a lack of understanding about the combined effect of chemical additives and asphalt emulsion on the recycled mixture performance.

The objective of this research is to investigate the effect of different chemical additives on the performance properties of asphalt emulsion recycled mixture. A mix design procedure based on the selection of optimum premix water content and optimum emulsion content is proposed. The performance of the recycled mixtures was evaluated by indirect tensile strength (ITS) test, moisture susceptibility test, rutting resistance test, and low temperature bending test. Furthermore, this research also provides insight into the interface adhesive mechanisms of the recycled mixture with emulsion and cement by observing the interface microstructure between the cement asphalt mastic and RAP.

\section{Materials}

The reclaimed asphalt pavement (RAP) was obtained directly from cold milling on site of distressed asphalt pavement. The RAP surface contained $4.2 \%$ asphalt binder by weight of RAP according to the results of Rotavapor extraction test. The moisture content of RAP was $0.9 \%$ of RAP weight. The performance properties of aged asphalt binder in RAP are given in Table 1 by the standard test procedures in JTG E20-2011 [17]. The design limits and gradation used in this study are shown in Figure 1. The gradation of RAP is within the required range of pavement recycling specification [18]. The selected mixing grade emulsion was slow-setting cationic asphalt emulsion. The physical properties of the emulsion are provided in Table 2 using test procedures in JTG E20-2011 [17]. The chemical materials, including hydrated lime (HL), type II composite Portland cement (CPC), and ground-granulated blast-furnace slag (GGBF), were used in combination with asphalt emulsion. The CPC content was adapted from $1.5 \%$ to $3.5 \%$ at $1 \%$ intervals based on the practical experience. In the composite additives of $\mathrm{HL}$ and GGBF, the mass ratio of $\mathrm{HL}$

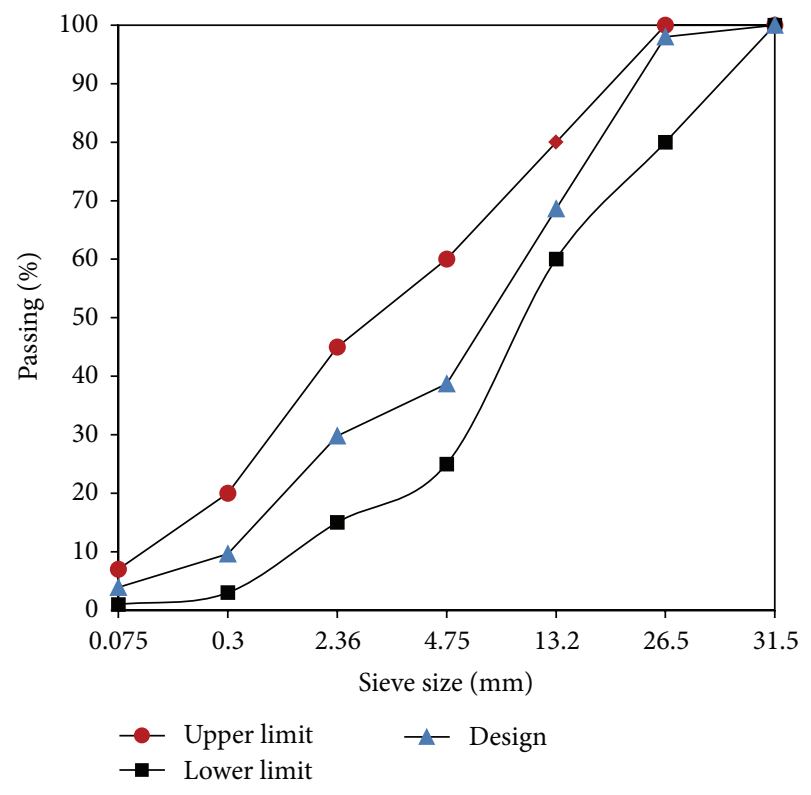

FIGURE 1: Gradation of RAP.

to GGBF was 1:3. The other chemical additive content was selected according to the test results of the mixture with CPC. In order to understand the physical and chemical properties of the additives, the Brunauer-Emmett-Teller surface area and methylene blue value were also tested in this study. The basic properties of these chemical materials are presented in Table 3 according to test methods in JTG E42-2005 [19].

\section{Mixture Design and Test Methods}

3.1. Mixture Design. Although universal accepted mix design procedure for asphalt emulsion recycled mixture is not available at present, guidelines have been developed by several agencies based on laboratory tests [20,21]. In this study, the recycled mixtures were designed using the modified Marshall volumetric mix design method.

During mixing of the recycled mixtures, the premix water was added in RAP before the addition of asphalt emulsion. Then different chemical materials were added to produce the mixture. Specimens were prepared at 75 blows per side with Marshall hammer. All compacted samples were left in the mold and cured at room temperature for $24 \mathrm{~h}$. After initial curing, the samples were demolded and cured in a forced draft oven at $60^{\circ} \mathrm{C}$ for $72 \mathrm{~h}$. The cured samples were allowed to cool at room temperature at least $24 \mathrm{~h}$ before the performance test.

The most important steps of aforementioned procedures were to determine the optimum premix water content (OPWC) and optimum emulsion content (OEC). The OPWC varies along with water in the emulsion and water content in RAP. Since the asphalt droplet in the emulsion is in the solid or semisolid state at room temperature, it is reasonable to conclude that water content dominates the workability and compactability of the mixture. When the RAP gradation, chemical additive types, and content are invariant, it is appropriate to assume that the summation of OPWC and 
TABLE 3: The basic properties of chemical additives.

\begin{tabular}{lccccc}
\hline Type of additives & $\begin{array}{c}\text { Specific gravity } \\
\left(\mathrm{g} / \mathrm{cm}^{3}\right)\end{array}$ & $\begin{array}{c}\text { BET surface area } \\
\left(\mathrm{m}^{2} / \mathrm{g}\right)\end{array}$ & $\begin{array}{c}\text { Methylene blue value } \\
(\mathrm{g} / \mathrm{kg})\end{array}$ & $\begin{array}{c}\mathrm{CaO} \\
(\%)\end{array}$ & $\begin{array}{c}\mathrm{SiO}_{2} \\
(\%)\end{array}$ \\
\hline $\mathrm{CPC}$ & 2.878 & 4.258 & 0.47 & 14.8 & 52.9 \\
$\mathrm{HL}$ & 2.329 & 7.029 & 0.52 & 62.5 & - \\
GGBF & 2.381 & 6.415 & 0.18 & 39.3 & 34.2 \\
\hline
\end{tabular}

water in asphalt emulsion is constant. In order to determine OPWC, the asphalt emulsion was assumed at $4 \%$ by the weight of RAP. Mixes were prepared with premix water contents ranging from $1.5 \%$ to $3.5 \%$ at $0.5 \%$ intervals. A study indicated that the OPWC of asphalt emulsion mixture corresponding to the maximum density is a little greater than the OPWC corresponding to the maximum ITS [10]. Considering the added free water has an adverse impact on the performance of the recycled mixture, the OPWC was determined according to maximum ITS for a given mix with $4 \%$ asphalt emulsion. It is obvious that the OPWC need to be adjusted when the emulsion content was not $4 \%$. To determine OEC, the recycled mixtures were prepared with emulsion contents ranging from $3.0 \%$ to $5.5 \%$ at $0.5 \%$ intervals. Simultaneously, the OPWC was adjusted according to the emulsion content. After curing, the ITS of specimens were tested. The OEC was defined as the emulsion content that corresponded to the maximum ITS for a given mix. Once OEC was determined, the corresponding OPWC could be easily calculated based on the aforementioned assumption.

For each chemical material, the OEC and OPWC should be determined before preparing specimens according to the described design procedures. After compaction and curing, volumetric and performance properties of the recycled mixtures were investigated. The bulk and maximum specific gravities of mix samples were measured by the vacuum sealing method at $25^{\circ} \mathrm{C}$. After first submerging specimens in $15^{\circ} \mathrm{C}$ water for 1 hour to achieve a uniform testing temperature, the indirect tensile test (ITS) was conducted immediately.

3.2. Moisture Susceptibility Test. Moisture damage in asphalt pavement has been considered as a major problem encountered by pavement engineers all over the world. In hot asphalt mixture, moisture existing in air voids degrades the interface bonding between asphalt and aggregates and even leads to the stripping of asphalt films from aggregate surfaces [22]. During the mix design of the emulsion recycled mixture, water was introduced into the aggregates to increase the workability of the mixture. Wet aggregates, added water, and water in the emulsion adversely impact the cohesion of asphalt mastic and the adhesion of mastic aggregate. Adhesion and cohesion failures lead to moisture damage. To combat moisture damage, the potential moisture resistance ability of the preliminary designed recycled mixtures should be verified by moisture susceptibility test.

In this study, moisture resistance was evaluated using the soaked ITS test and the freeze thaw ITS test, which are both widely used to characterize moisture resistance of hot asphalt mixture. A study also recommended evaluating the moisture resistance of cold asphalt emulsion mixture by these two methods [23]. Moisture susceptibility of the recycled mixture was appraised by soaked ITS test and freeze thaw cycle test. The air void of specimens was equal to that of the mix design results. For the soaked ITS test, the samples were soaked in a $25^{\circ} \mathrm{C}$ water bath for $23 \mathrm{~h}$ and then immersed in $15^{\circ} \mathrm{C}$ water for $1 \mathrm{~h}$. Moisture damage was evaluated by using the soaked tensile strength ratio (TSR), which was defined as the percentage ratio of soaked to dry tensile strength at $15^{\circ} \mathrm{C}$. To evaluate the resistance of freeze thaw damage, the $55-88 \%$ of air voids in specimens should be filled by water. Then the wrapped samples were conditioned by one freeze thaw cycle according to the JTG E20-2011 procedures [17]. Finally, the conditioned and unconditioned specimens were placed in $25^{\circ} \mathrm{C}$ water bath for $2 \mathrm{~h}$. All the samples were tested by $25^{\circ} \mathrm{C}$ ITS test at a rate of $50 \mathrm{~mm} / \mathrm{min}$. Similar to the soaked TSR, the freeze thaw TSR was defined as the percentage ratio of conditioned ITS to unconditioned ITS.

3.3. Rutting Test. Rutting resistance ability of the recycled mixture should be evaluated to avoid potential permanent deformation of the overall pavement structure. Popular rutting resistance test methods of hot asphalt mixture include static creep test and wheel tracking test [17]. In this study, the rutting resistance of the recycled mixture was evaluated by a wheel tracking test. The mixtures were compacted into slab specimens by a steel roller. The air void of slab specimens was the same as that of mix design. The compacted samples were left at room temperature for $24 \mathrm{~h}$ and then put at $60^{\circ} \mathrm{C}$ in a forced draft oven for $72 \mathrm{~h}$. During curing, the samples were maintained in the compaction molds to avoid the change of the geometry. After curing, the specimens were cooled at room temperature for $24 \mathrm{~h}$ and tested at a temperature of $60^{\circ} \mathrm{C}$ $\pm 1^{\circ} \mathrm{C}$. The $0.7 \mathrm{MPa}$ loading was performed by a solid rubber tire that moved on the sample surface at the speed of 42 passes per minute. The output of the test was the rut depth (RD) and the dynamic stability (DS). DS was defined as the number of wheel passes per $1 \mathrm{~mm}$ deformation between 45 and $60 \mathrm{~min}$ during the test period.

3.4. Low Temperature Bending Test. Although hot asphalt mixture overlay is always used on the surface of cold recycled base course materials, the recycled mixture can easily cause cracking in cold region. A three-point flexural beam test at $-10^{\circ} \mathrm{C}$ was adopted to evaluate the cracking resistance ability of the recycled mixture following a procedure in JTG E20-2011 [17]. In this test, a beam specimen with $250 \mathrm{~mm} \times$ $30 \mathrm{~mm} \times 35 \mathrm{~mm}$ was loaded at the midspan to get vertical deflection at a rate of $50 \mathrm{~mm} / \mathrm{min}$ until failure. The applied load and vertical deflection were measured and recorded by data collection system. The flexural failure strength, flexural 
tensile failure strain, and stiffness were calculated based on elementary beam theory. The fracture energy density, which was defined as the area values under stress-strain curve up to peak loading, was the potential energy required for resistant cracking of the recycled mixture. It was also calculated and viewed as an index of evaluating the cracking resistance of the recycled mixture.

3.5. ESEM Test. Environmental scanning electron microscope (ESEM) is a state-of-the-art high resolution research instrument. It is a development of high vacuum scanning electron microscope. The advantage of ESM is that wet and insulating specimens can be examined without prior specimen preparation. In this study, a Philips XL30 ESEM was used to observe the interface microstructure in the recycled mixture. After curing, the fractured specimens were cubed to dimensions of $1.5 \mathrm{~cm}$ by $1.5 \mathrm{~cm}$ and coated with gold for ESEM analysis. During the test, the fracture surface of specimens was observed by ESEM. A very thin coating of gold can provide the needed conductivity and can offer protection for material surface.

\section{Test Results and Discussion}

4.1. Mixes Design Results. The control mixture was composed of $100 \%$ RAP and asphalt emulsion. The chemical additives were introduced to replace the same weight of RAP passing the $0.075 \mathrm{~mm}$ sieve size. As described in Section 3.1, the OPWC and OEC of the recycled mixtures with different chemical additives were both determined by ITS test. The air void content of the mixtures was calculated by the test results of bulk specific gravity and theoretical maximum specific gravity. The test results of the OPWC, OEC, ITS, and void content are shown in Table 4.

When 1.5\% CPC is used, the OPWC and OEC of the recycled mixture are the same as those of the control mixture. As the CPC content increases, more premix water is needed because the interaction between cement and emulsion influenced the workability of the mixture. Therefore, the OPWC of the mixture with $2.5 \% \mathrm{CPC}$ increases compared with that of the mixture with $1.5 \% \mathrm{CPC}$. Moreover, the OEC of the mixture is decreased obviously when CPC content is $2.5 \%$. The higher OPWC leads to the increase of air void, so does the lower OEC. A study has demonstrated that hydration products exist in cement and asphalt emulsion composite mastic [10]. This indicates hydration product in asphalt acts as binding agent and reduces the requirement of the OEC. From test results of ITS in Table 4, it is found that the ITS of the control mixtures is improved by $35 \%$ when $1.5 \% \mathrm{CPC}$ is added. Furthermore, there is a significant positive correlation between ITS and CPC content. In theory, the hydration products in the cement asphalt mastic can modify the performance of asphalt binder. Therefore, the conclusion is that the cement content influences the optimum composition and mechanical strength of the recycled mixture with asphalt emulsion. Based on the lower OEC and higher ITS values, it is suggested to use $2.5 \%$ CPC to modify the control mixture.

Another objective of this study is to compare the effect of different additives on the performance of the recycled

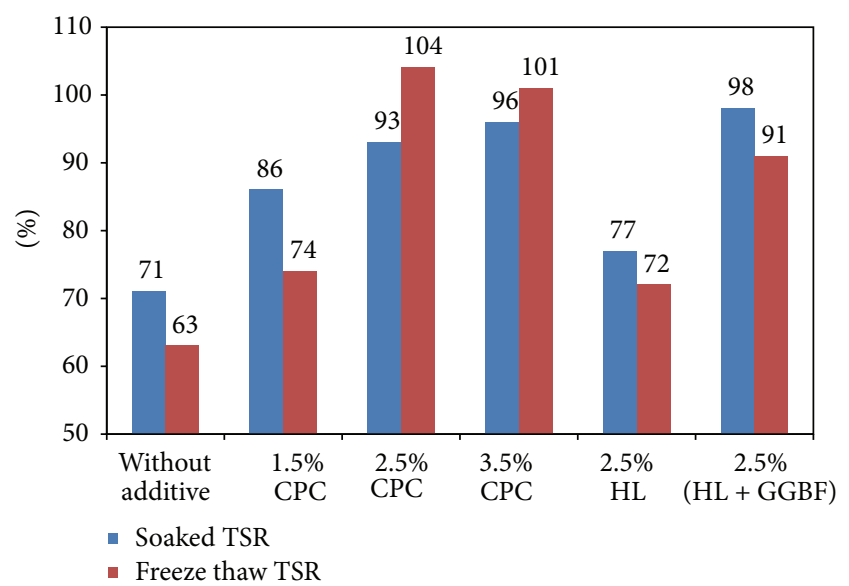

FIGURE 2: Soaked TSR and freeze thaw TSR results.

mixture. Since the preliminary determined CPC content is $2.5 \%$, other chemical additives also adopted the same content. The mix design results of the recycled mixtures with different chemical additives are provided in Table 4 . The strong water absorption ability of HL influences the workability of the mixture. It results in a much higher OPWC in the mixture. Furthermore, the chemical absorption between asphalt and HL improves the adhesion of asphalt mastic and RAP interface. The ITS of the control mixture is increased by $17 \%$. However, the improvement of $2.5 \%$ HL on ITS is even less than $1.5 \%$ CPC. It means that CPC is better material to improve the ITS than HL. When HL and GGBF are combined with asphalt emulsion, the OPWC of the control mixture is increased and OEC is decreased. This phenomenon is similar to the usage of CPC. Moreover, the ITS value of the recycled mixture with $\mathrm{HL}$ and GGBF approaches that of the mixture with CPC. A study has shown that the potential cementitious ability of GGBF can be activated by HL [23]. The hydration products from GGBF can also modify the performance of asphalt binder and the recycled mixture as these from CPC.

The technical guidelines of asphalt pavement recycling in China specify that the $15^{\circ} \mathrm{C}$ ITS of cold recycled mixture with asphalt emulsion and chemical additives should be higher than $0.4 \mathrm{MPa}$. The air void content should be between $9 \%$ and $14 \%$ [18]. For ITS values, all the recycled mixture can satisfy the requirement. Although air void content lower than $9 \%$ is advantageous to the durability of the recycled mixture, the lower OEC is beneficial to construction cost. Therefore, the $2.5 \%$ CPC or a combination of HL and GGBF is recommended to design the emulsion recycled mixture.

4.2. Moisture Susceptibility. Results of moisture resistance testing are provided in Table 5. The percentages of soaked TSR and freeze thaw TSR were calculated using previous definition and shown in Figure 2. The design specification of the emulsion recycled mixture in China recommends that the percentage of soaked TSR and freeze thaw TSR should be higher than $75 \%$ and $70 \%$, respectively [18]. For the recycled mixture only with asphalt emulsion, it cannot satisfy the specification requirement of moisture resistance. When $\mathrm{CPC}$ is used in combination with asphalt emulsion, both the 
TABLE 4: Mix design results of asphalt emulsion recycled mixtures.

\begin{tabular}{|c|c|c|c|c|}
\hline Type of additives & OPWC (\%) & OEC (\%) & Air void (\%) & $15^{\circ} \mathrm{C}$ dry ITS (MPa) \\
\hline Without additive & 2.0 & 5.0 & 8.0 & 0.51 \\
\hline $1.5 \% \mathrm{CPC}$ & 2.0 & 5.0 & 8.2 & 0.69 \\
\hline $2.5 \% \mathrm{CPC}$ & 2.5 & 3.5 & 10.1 & 0.99 \\
\hline $3.5 \% \mathrm{CPC}$ & 3.0 & 3.5 & 9.4 & 1.12 \\
\hline $2.5 \% \mathrm{HL}$ & 3.0 & 5.0 & 8.5 & 0.60 \\
\hline $2.5 \%(\mathrm{HL}+\mathrm{GGBF})$ & 3.0 & 4.0 & 10.7 & 1.03 \\
\hline
\end{tabular}

TABLE 5: Results of moisture susceptibility tests (three replicates).

\begin{tabular}{lcccccccc}
\hline \multirow{2}{*}{ Type of additives } & \multicolumn{2}{c}{ Dry ITS (MPa) } & \multicolumn{2}{c}{ Soaked ITS (MPa) } & ITS without freeze thaw (MPa) & \multicolumn{2}{c}{ Freeze thaw ITS (MPa) } \\
& AVE & SD & AVE & SD & AVE & SD & AVE & SD \\
\hline Without additive & 0.51 & 0.017 & 0.36 & 0.034 & 0.28 & 0.021 & 0.18 & 0.033 \\
$1.5 \%$ CPC & 0.69 & 0.031 & 0.59 & 0.05 & 0.51 & 0.011 & 0.38 \\
$2.5 \%$ CPC & 0.99 & 0.024 & 0.92 & 0.033 & 0.83 & 0.033 & 0.86 \\
$3.5 \%$ CPC & 1.12 & 0.041 & 1.07 & 0.021 & 0.92 & 0.017 & 0.93 \\
$2.5 \%$ HL & 0.60 & 0.022 & 0.46 & 0.034 & 0.35 & 0.053 & 0.019 \\
$2.5 \%$ (HL + GGBF) & 1.03 & 0.051 & 1.01 & 0.061 & 0.82 & 0.049 & 0.032 \\
\hline
\end{tabular}

$\mathrm{AVE}=$ average, $\mathrm{SD}=$ standard deviation

percentages of soaked TSR and freeze thaw TSR of the control mixture are improved. The TSR values in Figure 2 clearly manifest that the moisture resistance ability of the recycled mixture satisfies the specification requirement when only $1.5 \%$ CPC is added. The TSR results of the recycled mixture with HL also meet the requirement of moisture resistance. However, the ITS and TSR values of the mixture with $2.5 \% \mathrm{HL}$ and emulsion are lower than those of the mixture with emulsion and $1.5 \% \mathrm{CPC}$. This indicates that $\mathrm{HL}$ is inferior to $\mathrm{CPC}$ as an antimoisture damage additive. When HL and GGBF are used in combination with the emulsion, the ITS and TSR values of the mixture are close to those of the recycled mixture with $2.5 \%$ CPC. These results imply the moisture resistance ability of the control mixture is improved significantly by a combination of HL and GGBF. The modification effect of hydration products on asphalt emulsion is far superior to the physical and chemical absorption between asphalt emulsion and HL. Therefore, to improve moisture resistance, most effective additive is CPC or a combination of HL and GGBF.

4.3. Rutting. Results of rutting test are presented in Figure 3. The DS of the mixture is proportional to CPC content, but the $\mathrm{RS}$ is inversely proportional to CPC content. For the mixture with $2.5 \%$ CPC, the DS is increased by a factor of 11 and $\mathrm{RD}$ is decreased by $45 \%$ compared with the control mixture. To compare CPC with other materials, the content of every chemical additive is fixed at $2.5 \%$. When HL is adopted, the $\mathrm{RD}$ of the control mixture is decreased by $30 \%$ and DS is increased by $27 \%$. But the improvement of $2.5 \% \mathrm{HL}$ on rutting resistance is still lower than $1.5 \% \mathrm{CPC}$. When $\mathrm{HL}$ and GGBF are used in combination, the RD decreases by approximately $67 \%$ and the DS increases by a factor of 12 . Therefore, the most effective additive for rutting resistance is CPC or a combination of HL and GGBF. This conclusion is consistent with ITS and moisture susceptibility results.

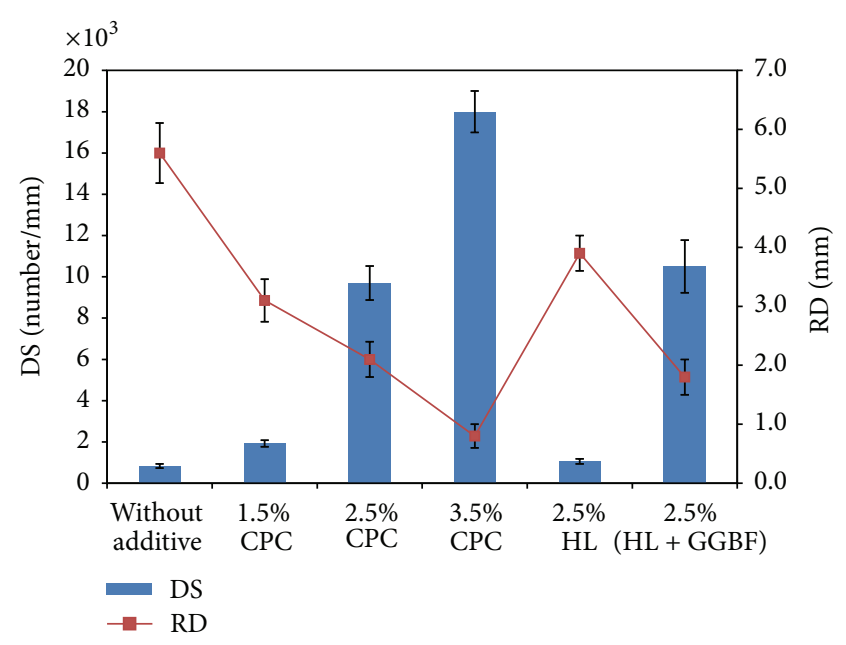

FIGURE 3: Rutting test results.

4.4. Low Temperature Bending Test. Test results are shown in Figures 4 and 5. The results in Figure 4 indicate the failure stress of the control mixture is improved but the failure strain is decreased as CPC content increases. This is the reason that the stiffness of the control mixture in Figure 5 is improved obviously by CPC. HL or a combination of HL and GGBF also brings similar trend as CPC. Therefore, it is difficult to evaluate the effect of chemical additives on the cracking resistance of the emulsion recycled mixture only based on failure stress or failure strain. A different trend is shown for fracture energy density results in Figure 5. It is observed that the fracture energy density is proportional to CPC content. The maximum fracture energy density is reached at $2.5 \%$ CPC. When different chemical additives are used, the fracture energy density of the control mixture is also improved 


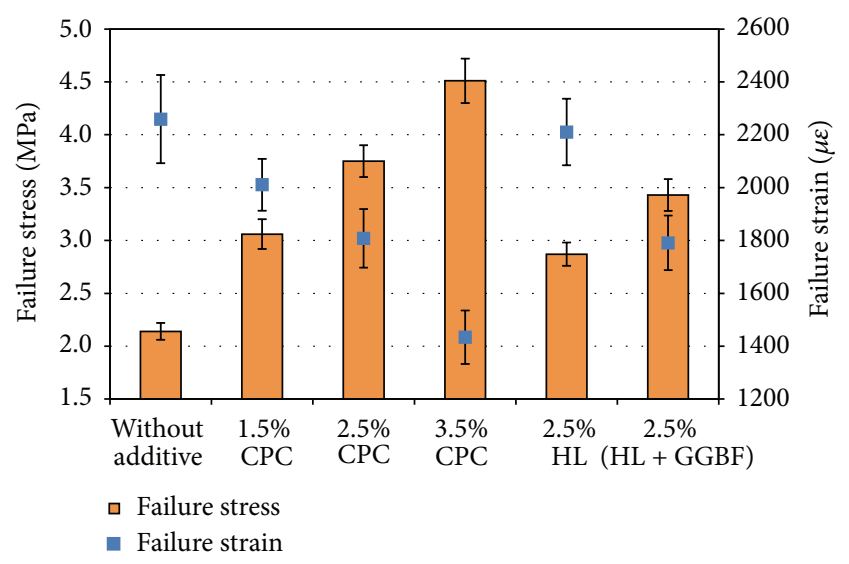

Figure 4: Failure stress and strain.

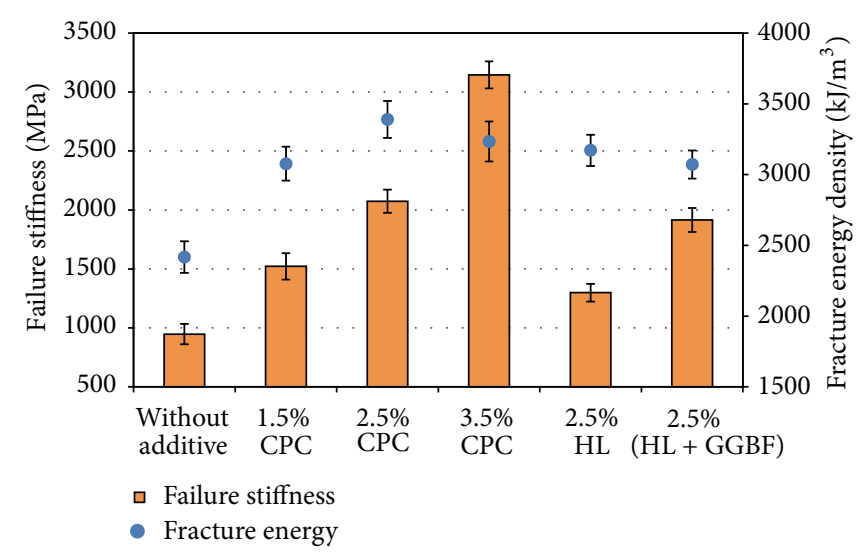

FIGURE 5: Failure stiffness and fracture energy density.

significantly. Therefore, chemical additives can modify the cracking resistance of the emulsion recycled mixture based on fracture energy density results. It is necessary to continue investigating the cracking resistance of the recycled mixture by fracture energy conception.

4.5. Interface Microstructure. To understand its performance, the microstructure images of the recycled mixture were observed by an environmental scanning electron microscope (ESEM). In the asphalt emulsion mixture, the interface modification of cement is superior to that of the other chemical additives cement [23]. Therefore, this study focuses on the interface of recycled mixture with asphalt emulsion and CPC. The recycled mixture with 2.5\% CPC and 3.5\% asphalt emulsion was cured according to the aforementioned curing procedures. In order to compare with the control mixture, the interface between RAP and asphalt emulsion was also observed. The ESEM photographs are shown in Figures 6,7 , and 8 .

The interface ESEM photograph between RAP and asphalt emulsion is provided in Figure 6. Although it is difficult to distinguish the aged asphalt mastic and new asphalt emulsion binder in Figure 6, it is obvious that new binder can bond with the RAP surface directly. However, the stiffness discrepancy between new asphalt mastic and aged asphalt

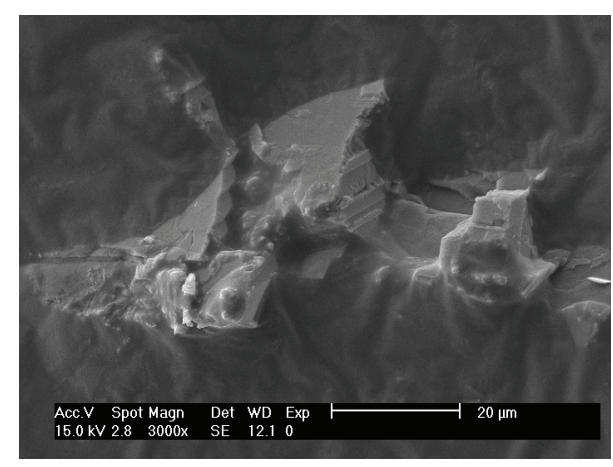

FIGURE 6: Interface between RAP and asphalt emulsion.

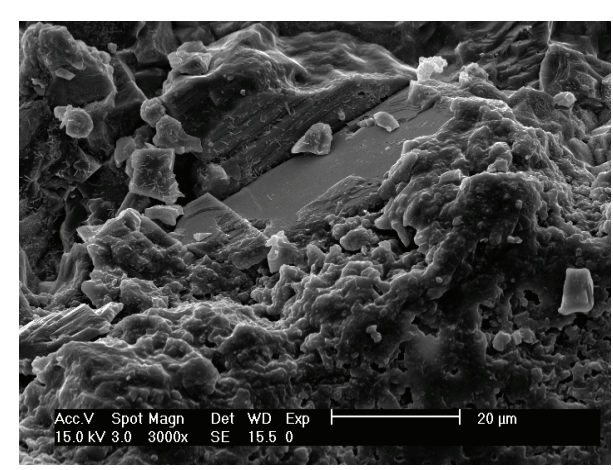

FIGURE 7: Interface between RAP and asphalt emulsion.

mastic leads to the inconsistent deformation between these mastics. Therefore, the ITS, moisture resistance, and rutting resistance of the mixture with asphalt emulsion cannot meet the requirement of traffic loading. From the interface photograph between RAP and asphalt emulsion in Figure 7, it can be observed that the compound substances with different structures exist in the interface zone of the recycled mixture. The hydration reaction of cement in asphalt emulsion leads to the results that cement asphalt mastic manifests the special morphology of hydration products. Moreover, it can be found that cement asphalt mastic bonds directly and closely with RAP. The interface ESEM photograph with smaller scale is provided in Figure 8 . It can be observed clearly that hydration products even pierce the asphalt film and bond with the aged asphalt mastic on the surface of RAP. If there are no rejuvenating agents in asphalt emulsion, it is extremely difficult for only asphalt emulsion to restore the rheological performance of aged asphalt [23]. However, the hydration products can increase the stiffness of asphalt binder and lower the stiffness difference between new asphalt mastic and aged asphalt mastic. Concurrently, hydration products consume the interface water and increase the adhesion strength between new asphalt mastic and aged asphalt mastic. Therefore, the bonding strength between new asphalt mastic and RAP is improved significantly by hydration products. This mechanism can explain why cementitious materials improve the ITS, moisture resistance, rutting, and low temperature bending resistance of the emulsion recycled mixture. 


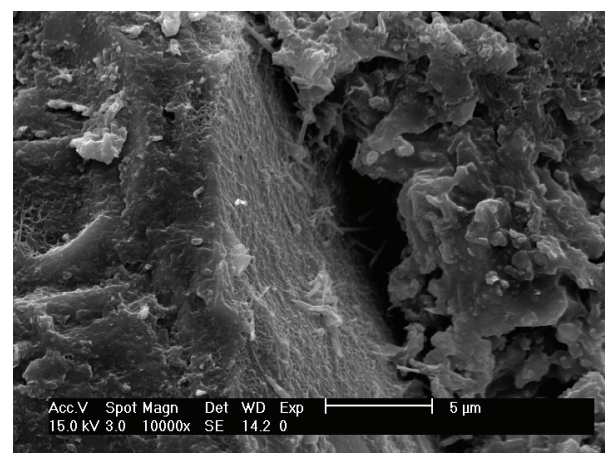

Figure 8: Interface of aged asphalt mastic and cement asphalt mastic.

\section{Conclusions}

Results discussion and analysis lead to the following conclusions:

(1) The mix deign results of the control mixture are affected by the CPC contents and chemical additives types. The proper CPC content can lower asphalt content and improve the ITS of the control mixture significantly. This conclusion can be found when a combination of HL and GGBF is added into the control mixture with the same content as CPC. Therefore, it is concluded that the hydration products from CPC or a combination of HL and GGBF behave as additional binder material in the asphalt emulsion recycled mixture.

(2) The moisture resistance ability and rutting resistance ability of the emulsion recycled mixture were proportional to CPC content. The CPC, HL, and a combination of HL and GGBF can improve these two properties of the control mixture at different levels. To antirutting and moisture damage of the control mixture, it is suggested to use CPC or the combination of $\mathrm{HL}$ and GGBE. These two chemical additives are both far superior to HL.

(3) The low temperature bending failure stress of the control mixture is increased but the failure strain and stiffness are decreased as CPC contents increase or the usage of other chemical additives. However, the fracture energy density of the control mixture shows the maximum values with $2.5 \%$ CPC. And it is also improved with addition of chemical additives. Therefore, it is recommended to evaluate the cracking resistance of the mixtures with chemical additives by fracture energy conception.

(4) According to ESEM analysis, it is concluded that hydration products can increase the stiffness and cohesion of the new asphalt mastic. Moreover, hydration products can improve the interface adhesion strength between asphalt mastic and RAP. This mechanism can explain the effect of chemical additive on the performance properties of the recycle mixture with emulsion.

\section{Conflict of Interests}

The author declares that there is no conflict of interests regarding the publication of this paper.

\section{Acknowledgments}

This research is supported by Natural Science Basic Research Plan in Shaanxi Province of China (no. 2014JQ2-5026), China Postdoctoral Science Foundation Funded Project (no. 2014M562359), and Scientific Research Foundation for the Returned Overseas Chinese Scholars, State Education Ministry.

\section{References}

[1] A. E. Alkins, B. Lane, and T. Kazmierowski, "Sustainable pavements: environmental, economic, and social benefits of in situ pavement recycling," Transportation Research Record, vol. 2084, pp. 100-103, 2008.

[2] S. Cross, W. Chesner, H. Justus, and E. Kearney, "Life-cycle environmental analysis for evaluation of pavement rehabilitation options," Transportation Research Record, vol. 2227, pp. 43-52, 2011.

[3] Asphalt Institute, Asphalt Cold Mix Recycling Manual Series No.21(MS-21), Asphalt Institute, Lexington, Ky, USA, 1st edition, 1983.

[4] T. Quick and W. S. Guthrie, "Early-age structural properties of base material treated with asphalt emulsion," Transportation Research Record, vol. 2253, pp. 30-40, 2011.

[5] A. James, Overview of Asphalt Emulsion, Asphalt Emulsion Technology, Transport Research Circular no. E-C102, Transportation Research Board, Washington, DC, USA, 2006.

[6] K. Khweir, D. Fordyce, D. Strickland, and J. Read, "Effect of curing time and the performance of cold asphalt mixtures," in Proceedings of the 3rd Eurasphalt and Eurobiume Congress, pp. 144157, Vienna, Austria, May 2004.

[7] R. L. Terrel and C. K. Wang, "Early curing behavior of cement modified asphalt emulsion mixtures," Journal of the Association of Asphalt Paving Technologists, vol. 40, pp. 108-125, 1971.

[8] S. F. Brown and D. Needham, "A study of cement modified bitumen emulsion mixtures," in Asphalt Paving Technology 2000, pp. 92-121, usa, March 2000.

[9] S. Oruc, F. Celik, and M. V. Akpinar, "Effect of cement on emulsified asphalt mixtures," Journal of Materials Engineering and Performance, vol. 16, no. 5, pp. 578-583, 2007.

[10] S. Du, "Interaction mechanism of cement and asphalt emulsion in asphalt emulsion mixtures," Materials and Structures, vol. 47, no. 7, pp. 1149-1159, 2014.

[11] R. Miro Recasens, F. E. Pérez Jiménez, and S. Castillo Aguilar, "Mixed recycling with emulsion and cement of asphalt pavements. design procedure and improvements achieved," Materials and Structures, vol. 33, no. 229, pp. 324-330, 2000.

[12] K. C. Kumar, D. S. N. V. Amar Kumar, R. M. Amaranatha, and R. K. Sudhakar, "Investigation of cold-in-place recycled mixes in India," International Journal of Pavement Engineering, vol. 9, no. 4, pp. 265-274, 2008.

[13] M. Bocci, A. Grilli, F. Cardone, and G. Ferrotti, "Full-depth reclamation for the rehabilitation of local roads: a case study," International Journal of Pavement Engineering, vol. 15, no. 3, pp. 191-201, 2014. 
[14] S. A. Cross, "Experimental cold in-place recycling with hydrated lime," Transportation Research Record, vol. 1684, pp. 186193, 1999.

[15] T. Thomas, A. Kadrmas, and J. Huffman, "Cold in-place recycling on us-283 in kansas," Transportation Research Record, vol. 1723, pp. 53-56, 2000.

[16] Y. Niazi and M. Jalili, "Effect of Portland cement and lime additives on properties of cold in-place recycled mixtures with asphalt emulsion," Construction and Building Materials, vol. 23, no. 3, pp. 1338-1343, 2009.

[17] Ministry of Transport of the People's Republic of China, JTJ E022011. Standard Test Methods of Bitumen and Bituminous Mixtures for Highway Engineering, China Communication Press, Beijing, China, 2011.

[18] Ministry of Transport of the People's Republic of China, JTG F41-2008. Technical Specifictaions for Highway Asphalt Pavement Recycling, China Communication Press, Beijing, China, 2008.

[19] Ministry of Transport of the People's Republic of China, “Test methods of aggregates for highway engineering," JTG E42-2005, China Communication Press, Beijing, China, 2005.

[20] K. Wayne Lee, "New mix-design procedure of cold in-place recycling for pavement rehabilitation," in Proceedings of the 82nd TRB Annual Meeting, Washington, DC, USA, January 2003.

[21] Asphalt Recycling and Reclaiming Association, Basic Asphalt Recycling Manual, Asphalt Recycling and Reclaiming Association, Annapolis, Md, USA, 2001.

[22] S. Caro, E. Masad, A. Bhasin, and D. N. Little, "Moisture susceptibility of asphalt mixtures, part 1: mechanisms," International Journal of Pavement Engineering, vol. 9, no. 2, pp. 81-98, 2008.

[23] S. Du, "Effect of different fillers on performance properties of asphalt emulsion mixture," Journal of Testing and Evaluation, vol. 42, no. 1, pp. 126-134, 2014. 

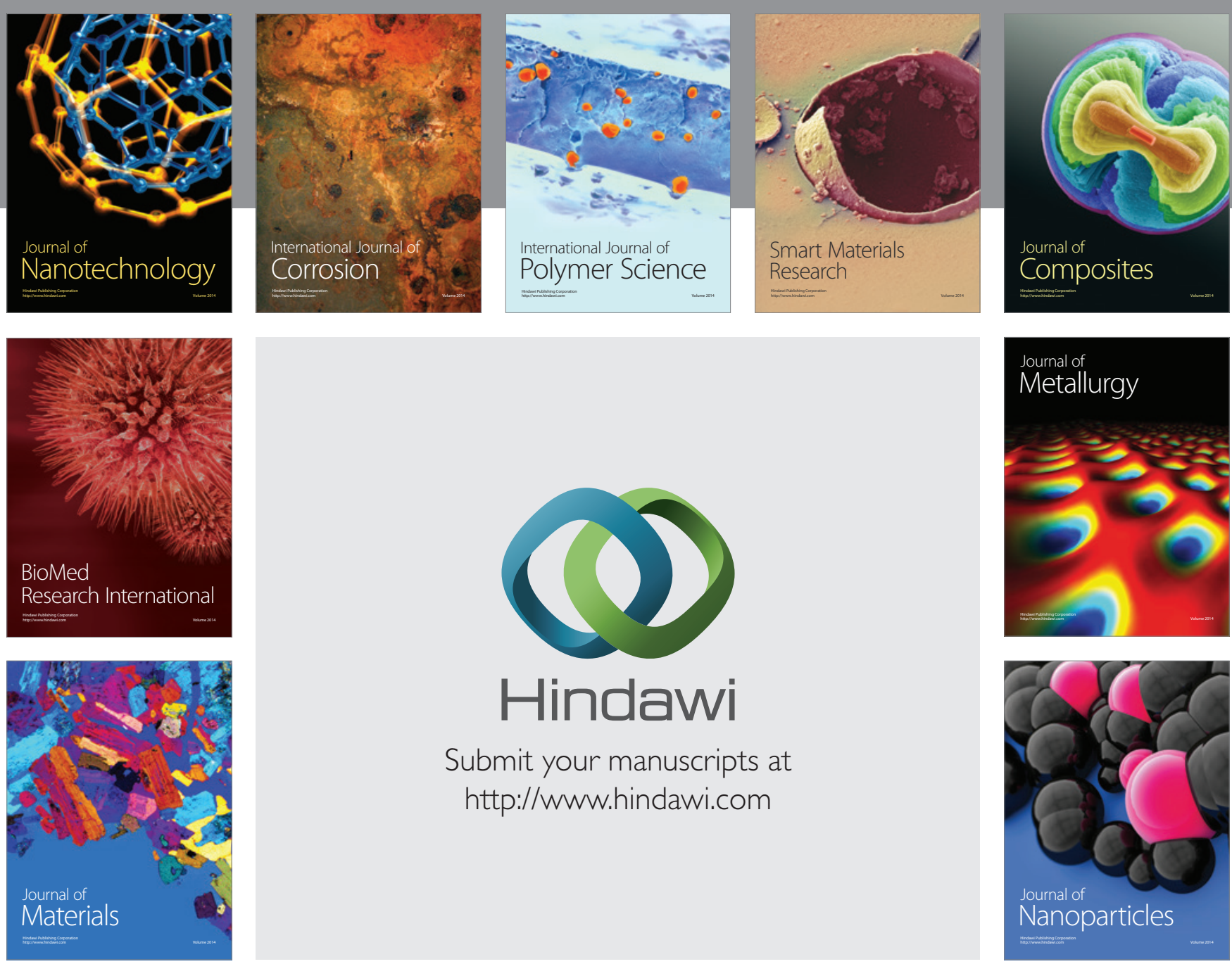

Submit your manuscripts at http://www.hindawi.com
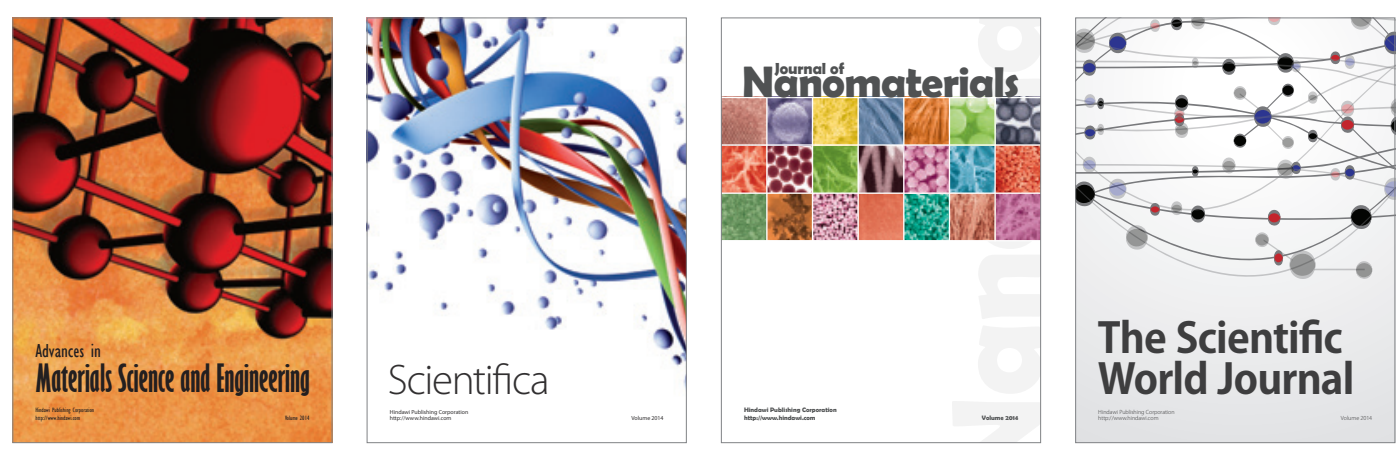

\section{The Scientific World Journal}
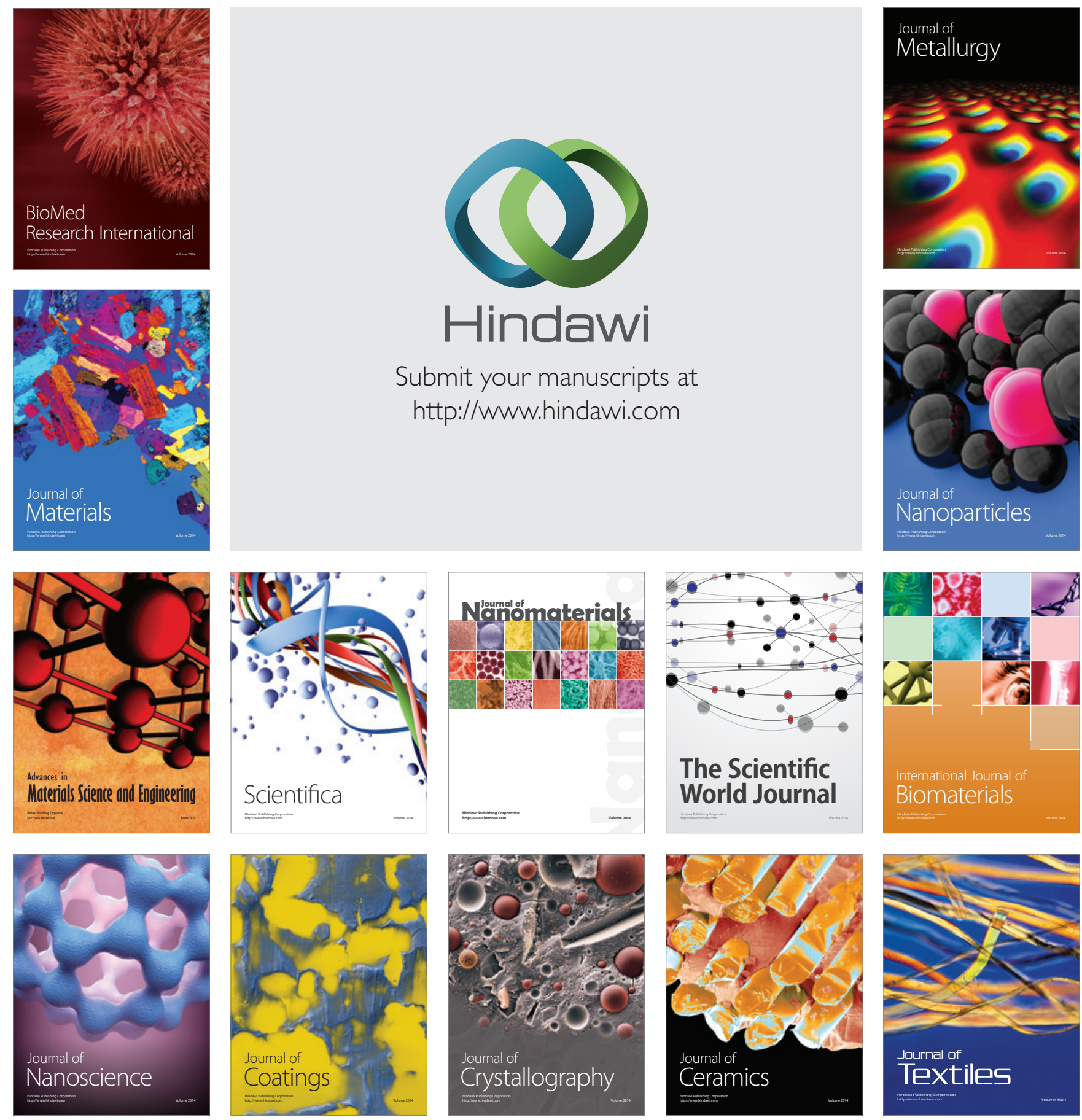